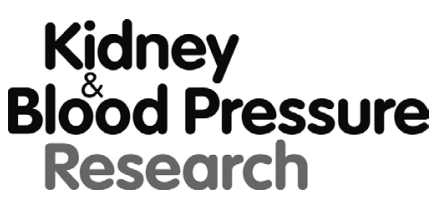

Kidney Blood Press Res 2018;43:1333-1343

DOI: $10.1159 / 000492592$

Published online: 10 August, 2018

Accepted: 1 August, 2018

This article is licensed under the Creative Commons Attribution-NonCommercial-NoDerivatives 4.0 International License (CC BY-NC-ND) (http//wuwwkargercom/Services/OpenAccessLicense). Usage and distribution for commercial purposes as well as any distribution of modified material requires written permission.

\title{
Combined Immunosuppressive Treatment May Improve Short-Term Renal Outcomes in Chinese Patients with Advanced IgA Nephropathy
}

\author{
Li Tan ${ }^{a, c} \quad$ Yi Tang ${ }^{a} \quad$ Wei Penga,c Bechu Shelley Mathew ${ }^{\mathrm{b}, c} \quad$ Wei Qin ${ }^{\mathrm{a}}$ \\ aDivision of Nephrology, Department of Medicine, West China Hospital, Sichuan University, Chengdu, \\ Sichuan, bDepartment of Anesthesiology, West China Hospital, Sichuan University, Chengdu, Sichuan, \\ 'West China School of Medicine, Sichuan University, Chengdu, Sichuan, China
}

\section{Key Words}

Immunoglobulin A nephropathy $(\operatorname{Ig} A) \cdot$ Corticosteroids $\bullet$ Immunosuppressive therapy $\bullet$ Renal survival

\begin{abstract}
Background/Aims: Treatment of advanced Immunoglobulin A nephropathy (IgAN) patients with estimated glomerular filtration rate (eGFR) below $45 \mathrm{~mL} / \mathrm{min}$ per $1.73 \mathrm{~m}^{2}$ remains inconsistent. The aim of this study is to compare the effects of corticosteroid and immunosuppressant therapies among these patients. Methods: A total of 201 adult patients with advanced IgAN (eGFR $<45 \mathrm{~mL} / \mathrm{min} / 1.73 \mathrm{~m}^{2}$ and proteinuria $>1 \mathrm{~g} / 24 \mathrm{~h}$ at biopsy) grouped into supportive care (SC), steroids alone (CS), and steroids plus immunosuppressant (IT) groups, were investigated between $30^{\text {th }}$ December 2002 and $30^{\text {th }}$ June 2016. The primary endpoint was the combined endpoint of a $50 \%$ decline in eGFR and/or end stage renal disease (ESRD: eGFR $<15 \mathrm{~mL} / \mathrm{min} / 1.73 \mathrm{~m}^{2}$ or maintenance renal replacement treatment). Responses to therapy included complete remission (CR: urinary protein excretion $<0.5 \mathrm{~g} / 24 \mathrm{~h}$, with eGFR decrease less than $10 \%$ baseline), partial remission (PR: proteinuria decrease by $>50 \%$ baseline, with eGFR decrease less than $10 \%$ baseline), no response (NR: proteinuria decrease $<50 \%$ baseline, or eGFR decrease $>10 \%$ baseline) and ESRD. Kaplan-Meier and Cox proportional hazards analyses were performed. Results: During the follow-up period (37.2 \pm 22.7 months), $6.8 \%$ patients in SC group, $25.0 \%$ in CS group, and $38.0 \%$ in IT group achieved CR or PR, while $78.4 \%, 62.5 \%$ and $49.3 \%$ patients in these 3 groups reached primary endpoint respectively ( $p$ $<0.001$ ). Three-year renal survival rates in SC and combined immunosuppressive treatment groups (CS and IT groups) were $33.8 \%$ vs $51.2 \%(p=0.02$ ), and 5 -year renal survival rates were $12.2 \%$ vs $21.3 \%(p=0.1)$ respectively. Multivariate Cox regression analysis showed that
\end{abstract}

L. Tan and Y. Tang contributed equally to this paper.

$\begin{array}{ll}\text { Wei Qin } & \text { Division of Nephrology, Department of Medicine, West China Hospital, Sichuan University, } \\ & \text { Chengdu, Sichuan (China) } \\ & \text { Tel. +86-28-85422338, Fax +86-028-8542-3341, E-Mail ddqstrike@163.com }\end{array}$




\section{Kidney Blood Pressure Research}

Kidney Blood Press Res 2018;43:1333-1343

\begin{tabular}{l|l}
\hline DOI: $10.1159 / 000492592$ & (C) 2018 The Author(s). Published by S. Karger AG, Basel
\end{tabular}

Published online: 10 August, 2018

www.karger.com $/ \mathrm{kb}$

Tan et al.: Combined Immunosuppressive Treatment for Advanced IgA Nephropathy

hypertension ( $H R=2.44,95 \%$ CI 1.51-3.95; $p<0.001)$, Scr $(H R=1.01,95 \%$ CI 1.00-1.01; $p$ $<0.001)$, T1-T2 lesion (HR $=1.99,95 \%$ CI 1.35-2.93; $p=0.001$ ) were independent indicators of poor renal outcome. Conclusion: Immunosuppressive treatment (CS and IT therapy) may improve short-term renal outcome compared with supportive treatment in advanced IgAN patients.

(C) 2018 The Author(s)

Published by S. Karger AG, Basel

\section{Introduction}

Immunoglobulin A nephropathy (IgAN) is one of the most common glomerulonephritis (GN) worldwide, accounting for nearly $45 \%$ of all primary GN cases [1, 2], and $20-40 \%$ of the patients developed into ESRD within 10 to 20 years from the onset of disease $[3,4]$. It is recommended to use corticosteroids rather than immunosuppressants in IgAN patients with a persistent proteinuria $\geq 1 \mathrm{~g} / \mathrm{d}$ after 3-6 months of optimized supportive care and an eGFR $>50 \mathrm{~mL} / \mathrm{min} / 1.73 \mathrm{~m}^{2}[5,6]$. However, no recommendation was made for patients with eGFR $<45 \mathrm{ml} / \mathrm{min} / 1.73 \mathrm{~m}^{2}$. Given that some studies supported the use of steroids or immunosuppressants [7-9] for these patients, which is also widely applied clinically, thus we conducted this study to explore whether corticosteroids or immunosuppressant therapies could improve the renal outcome of patients with advanced IgAN (eGFR $<45 \mathrm{~mL} / \mathrm{min} / 1.73$ $\mathrm{m}^{2}$ and mean proteinuria $\left.>1 \mathrm{~g} / 24 \mathrm{~h}\right)$.

\section{Materials and Methods}

\section{Patients and treatment}

1208 biopsy-proven IgAN patients were reviewed between 30th December 2002 and 30th June 2016 in this study. Patients with systemic diseases (systemic lupus erythematosus, diabetes mellitus, the Henoch-Schönlein purpura and liver cirrhosis, etc.) were excluded. Since there were no standard treatment guidelines for these patients, therapeutic regimens were determined by both the doctors' experience and the patients' willing based on current consensus. According to different treatment strategies, patients were divided into three groups: supportive care (SC), corticosteroids alone (CS) and corticosteroids plus immunosuppressant therapy (IT). Patients in SC group only received optimized supportive care with full dose angiotensin-converting-enzyme inhibitor (ACEi) or angiotensin receptor blockers (ARB) to achieve target blood pressure (BP $<140 / 90 \mathrm{mmHg}$ ). Patients in CS group received optimized supportive care along with corticosteroids ( $0.5-1 \mathrm{mg} / \mathrm{kg}$ Prednisone daily, tapering down within 6 - 8 months). And patients in IT group received optimized supportive care along with corticosteroids (dosage as mentioned above) and immunosuppressant therapy (Cyclophosphamide $2 \mathrm{mg} / \mathrm{kg}$ daily for 3 months, or Mycophenolate Mofetil 1-2 g daily for 6-8 months). Regarding calcineurin inhibitors (CNI), such as cyclosporin A (CsA) or tacrolimus (Tac) were not recommended to treat IgAN yet, so patients treated with these drugs were excluded from this study. Patients were followed up for at least 12 months or shorter if they reached endpoint of study. This study complies with the principles of the Helsinki Declaration and was approved by The Ethics Committee of West China Hospital of Sichuan University. Written informed consents were signed by all the patients before treatment. Medication-related adverse events were carefully described to each patient. Patients refusing to take steroids or immunosuppressants, were given optimal supportive therapy.

\section{Measurements and renal pathology Data}

Clinical information (gender, age, medical history) and laboratory data such as serum albumin (Alb), serum creatinine (Scr), uric acid (UA), and $24 \mathrm{~h}$ urinary protein were collected at the time of biopsy. Patients were followed up monthly in West China Hospital. Renal pathology changes in all cases were graded by the Oxford classification [10]. Renal biopsies from all patients were reviewed by experienced pathologists. The updated Oxford Classification was applied in this study: mesangial hypercellularity (M0/M1); endocapillary hypercellularity (E0/E1); segmental glomerulosclerosis (S0/S1); tubular atrophy/interstitial fibrosis (T0/ $\mathrm{T} 1 / \mathrm{T} 2)$ [10] and cellular or fibrocellular crescents (C0/C1/C2) [11]. 


\section{Kidney Blood Pressure Research}

Kidney Blood Press Res 2018;43:1333-1343

\begin{tabular}{l|l}
\hline DOI: $10.1159 / 000492592$ & (C) 2018 The Author(s). Published by S. Karger AG, Basel
\end{tabular}

Published onlıne: 10 August, 2018

www.karger.com $/ \mathrm{kb}$

Tan et al.: Combined Immunosuppressive Treatment for Advanced IgA Nephropathy

Outcomes

Responses to therapy included complete remission (CR), partial remission (PR), no response (NR) and end stage renal disease (ESRD). CR was defined as urinary protein excretion $<0.5 \mathrm{~g} / 24 \mathrm{~h}$, with eGFR decrease less than $10 \%$ baseline. PR was defined as proteinuria decrease by $>50 \%$ baseline, with eGFR decrease less than $10 \%$ baseline. NR was defined as proteinuria decrease $<50 \%$ baseline, or eGFR decrease $>10 \%$ baseline. ESRD was defined as eGFR $<15 \mathrm{~mL} / \mathrm{min} / 1.73 \mathrm{~m}^{2}$ or maintenance renal replacement treatment. The primary endpoint was the combined endpoint of a 50\% decline in eGFR and/or ESRD.

Categorical data were analyzed using Chi-square tests or Fischer's exact test. Continuous variables were analyzed with ANOVA, Kruskal-Wallis H test, Student's t test or nonparametric Mann-Whitney U test. Categorical variables were presented as frequencies (percentages). Continuous variables are presented as mean \pm standard deviation (SD) or median [interquartile range (IQR)]. Multivariate Cox regression analysis was used to evaluate the crude effect of clinical and pathological variables on the renal outcomes. Hazard ratios (HRs) and their 95\% confidence intervals (CIs) were obtained in the adjusted regression analysis. All statistical analysis was performed by using IBM SPSS Statistics 22.0 software. Statistical significance was determined as $\mathrm{p}<0.05$.

\section{Results}

\section{Demographic and Clinicopathological Features of Patients}

Among the 1208 biopsy-proven IgAN patients reviewed, 201 patients meeting the inclusion criteria were further analyzed in this study (shown in Fig. 1). Demographic and clinicopathological features of these 201 patients were displayed in Table 1. It is noted that all patients included in this study were from a single ethnicity (Han Chinese). These patients were categorized into treatment groups: SC $(74,36.8 \%)$, CS $(56,27.8 \%)$ and IT $(71,35.3 \%)$. The average follow-up period was $37.2 \pm 22.7$ months (Table 1). Of all these 201 IgAN patients, $56.2 \%(n=113)$ patients were in chronic kidney disease (CKD) stage $3 \mathrm{~b}$, and $43.8 \%$ $(\mathrm{n}=88$ ) were in CKD stage 4 . The only significant difference was found in serum creatinine levels among these 3 groups. No differences in pathological changes scores were observed among these 3 groups. The clinicopathological features of these patients in different CKD stages were shown in Table 2. Comparison between stages CKD $3 \mathrm{~b}$ and CKD 4 patients indicated significant differences in mean arterial pressure (MAP) $(p=0.01)$, hypertension ratio ( $p=0.02)$, serum creatinine (Scr) level $(\mathrm{p}<0.001)$, eGFR level $(\mathrm{p}<0.001)$, urine protein amount $(\mathrm{p}=0.001)$ and serum albumin (Alb) level $(\mathrm{p}<0.001)$ (Table 2). No differences in pathological changes scores were observed between CKD stage $3 \mathrm{~b}$ and stage 4 patients.

\section{Treatment Response}

Therapy responses for different treatment regimens were listed in Fig. 2 and Table 3. Of all the 201 patients, $15.9 \%$ (32) patients achieved CR, 7.0\% (14) patients reached PR, $14.4 \%$ (29) patients ended in NR, and $62.7 \%$ (126) patients progressed to ESRD, while no patient died during the follow-up period. As shown in Fig. 2, the outcomes of patients in SC and IT groups were better than that of SC group patients who had considerably low incidences of CR and PR and a high incidence of ESRD $(\mathrm{p}<0.001)$.

In stage 3b CKD patients, incidences of CR or PR increased gradually from SC group, CS group to IT group (9.5\% vs $36.7 \%$ vs $46.3 \%$ ), however the proportion of progression to ESRD was opposite, which decreased through SC, CS and IT groups respectively $(73.8 \%$ vs $43.3 \%$ vs $34.1 \%$ ) ( $\mathrm{p}=0.007$ ). In stage 4 CKD patients, the tendency of achieving CR, PR ( $3.1 \%$ vs $11.5 \%$ vs $26.7 \%$ ) and progression to ESRD ( $84.4 .0 \%$ vs $84.6 \%$ vs $63.3 \%$ ) in different treatment groups were approximately similar to those in stage $3 \mathrm{~b}$ CKD patients $(\mathrm{p}=0.07)$. Notably, no stage 4 CKD patients with the treatment of SC achieved CR. 


\section{Kidney Blood Pressure Research}

Fig. 1. Flow diagram of patient progress and outcomes. Abbreviations: CKD, chronic kidney disease; SC, supportive care group; CS, corticosteroids; IT, immunosuppressive therapy;

$\mathrm{CR}$, complete remission; PR, partial remission; NR, no response; ESRD, end stage renal disease; CsA, cyclosporin A.

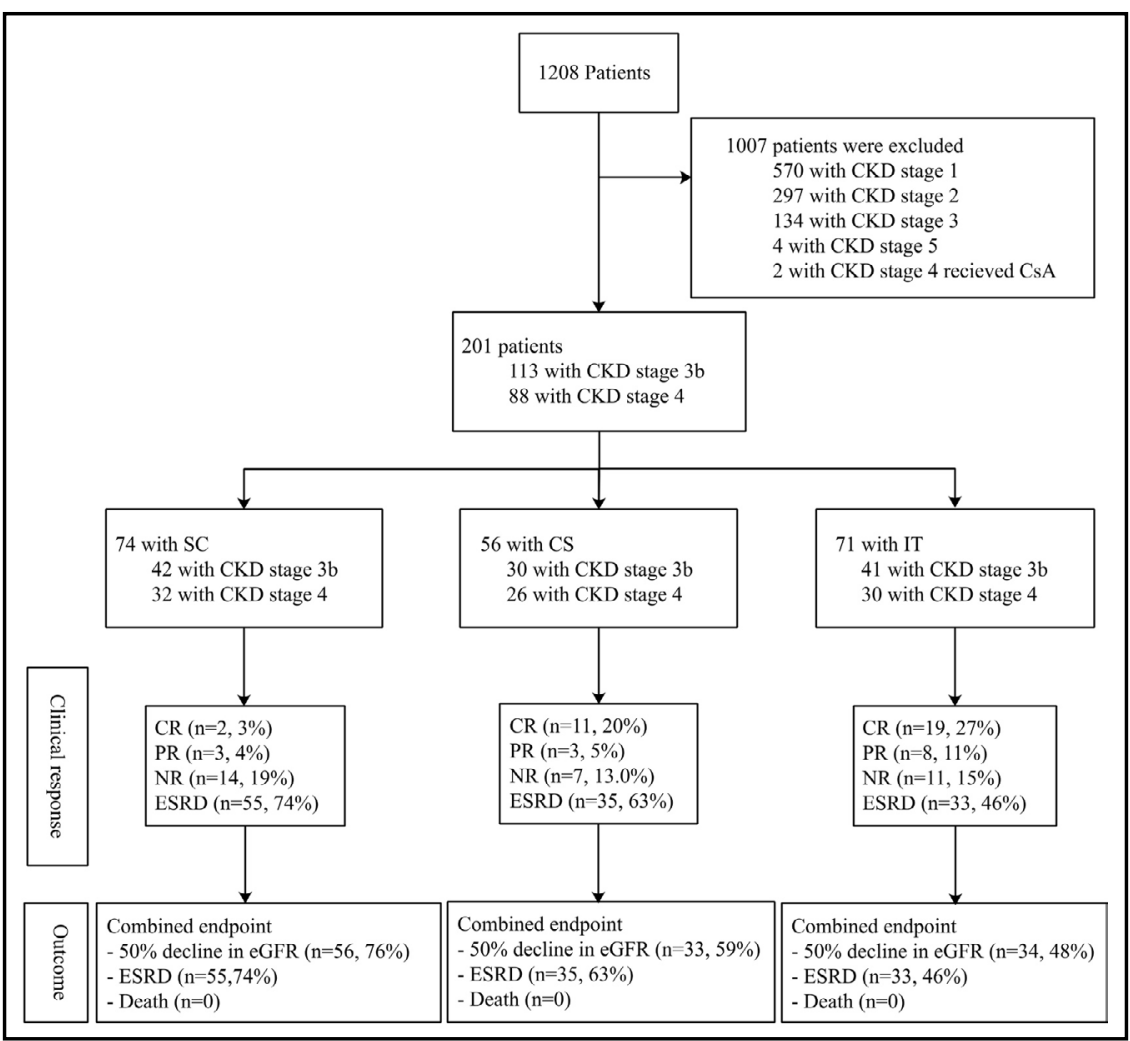

Table 1. Demographic and Clinicopathologic Features of IgAN Patients. Note: Values for categorical variables are given as number (percentage); values for continuous variables are given as mean \pm standard deviation or median (interquartile range). Abbreviations: MAP, mean arterial pressure; eGFR, estimated glomerular filtration rate; CKD, chronic kidney disease; $\mathrm{M}$, mesangial proliferation; $\mathrm{E}$, endocapillary proliferation; $\mathrm{S}$, segmental sclerosis; T, tubular atrophy/interstitial fibrosis; C, crescents; SC, supportive care group; CS, corticosteroids; IT, immunosuppressive therapy. * stands for $\mathrm{p}<0.05$

\begin{tabular}{|c|c|c|c|}
\hline \multirow{2}{*}{ Characteristics } & \multicolumn{3}{|c|}{ Groups } \\
\hline & $\mathrm{SC}(\mathrm{n}=74)$ & $\operatorname{CS}(n=56)$ & IT $(n=71)$ \\
\hline \multicolumn{4}{|l|}{ Clinical } \\
\hline Age (year) & $35.0[30.0-38.0]$ & $36.0[32.0-38.0]$ & $34.0[29.0-39.0]$ \\
\hline Female gender (\%) & $33(44.6)$ & $31(55.4)$ & $43(60.6)$ \\
\hline MAP (mmHg) & $116.0[110.0-120.0]$ & $113.0[98.0-117.0]$ & $111.0[98.0-117.0]$ \\
\hline Hypertension (\%) & $61(82.4)$ & $39(69.6)$ & $53(74.6)$ \\
\hline Serum creatinine $(\mu \mathrm{mol} / \mathrm{L}) *$ & $229.28 \pm 71.41$ & $209.34 \pm 55.44$ & $198.13 \pm 67.17$ \\
\hline eGFR $\left(\mathrm{mL} / \mathrm{min}\right.$ per $\left.1.73 \mathrm{~m}^{2}\right)$ & $31.29 \pm 8.71$ & $31.25 \pm 7.49$ & $30.82 \pm 8.55$ \\
\hline Urine protein $(\mathrm{g} / 24 \mathrm{~h})$ & $4.37 \pm 2.89$ & $3.74 \pm 3.03$ & $3.77 \pm 2.96$ \\
\hline Serum albumin (g/L) & $33.30 \pm 6.27$ & $32.93 \pm 10.17$ & $34.18 \pm 6.52$ \\
\hline Nephrotic syndrome (\%) & $24(32.4)$ & $10(17.9)$ & $15(21.1)$ \\
\hline Uric acid $(\mu \mathrm{mol} / \mathrm{L})$ & $411.0[284.0-522.0]$ & $372.0[284.0-522.0]$ & $385.0[284.0-484.0]$ \\
\hline \multicolumn{4}{|l|}{ CKD stage } \\
\hline Stage $3 b(\%)$ & $42(56.8)$ & $30(53.6)$ & $41(57.7)$ \\
\hline Stage $4(\%)$ & $32(43.2)$ & $26(46.4)$ & $30(42.3)$ \\
\hline \multicolumn{4}{|l|}{ Pathologic } \\
\hline \multicolumn{4}{|l|}{ Oxford Classification } \\
\hline M1 (\%) & $68(91.9)$ & $53(94.6)$ & $67(94.4)$ \\
\hline E1 (\%) & $8(10.8)$ & $4(7.1)$ & $5(7.0)$ \\
\hline S1 (\%) & $49(66.2)$ & $37(66.1)$ & $50(70.4)$ \\
\hline $\mathrm{T} 1 / \mathrm{T} 2$ (\%) & $34(45.9)$ & $24(42.9)$ & $29(40.8)$ \\
\hline $\mathrm{C} 1 / \mathrm{C} 2(\%)$ & $25(33.8)$ & $18(32.1)$ & $26(36.6)$ \\
\hline
\end{tabular}




\section{Kidney Blood Pressure Research}

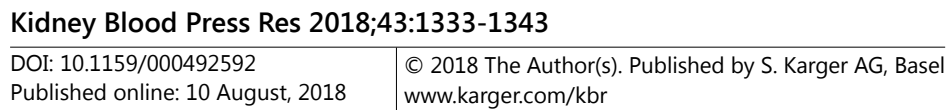

Table 2. Demographic and Clinicopathologic Features of IgAN Patients according to CKD Stage. Note: Values for categorical variables are given as number (percentage); values for continuous variables are given as mean \pm standard deviation or median (interquartile range). Abbreviations: MAP, mean arterial pressure; eGFR, estimated glomerular filtration rate; CKD, chronic kidney disease; M, mesangial proliferation; E, endocapillary proliferation; S, segmental sclerosis; T, tubular atrophy/interstitial fibrosis; C, crescents. * stands for $\mathrm{p}<0.05$

\begin{tabular}{|c|c|c|}
\hline Characteristics & CKD stage $3 b(n=113)$ & CKD stage $4(n=88)$ \\
\hline \multicolumn{3}{|l|}{ Clinical } \\
\hline Age (year) & $36.35 \pm 9.38$ & $34.78 \pm 9.19$ \\
\hline Female gender (\%) & $63(55.8)$ & $44(50.0)$ \\
\hline $\operatorname{MAP}(\mathrm{mmHg}) *$ & $108.98 \pm 12.49$ & $113.73 \pm 14.44$ \\
\hline Hypertension (\%) * & $79(69.9)$ & $74(84.1)$ \\
\hline Serum creatinine $(\mu \mathrm{mol} / \mathrm{L}) *$ & $170.0[146.0-193.0]$ & $250.0[220.0-300.0]$ \\
\hline eGFR $\left(\mathrm{mL} / \mathrm{min}\right.$ per $\left.1.73 \mathrm{~m}^{2}\right) *$ & $37.31 \pm 4.13$ & $23.15 \pm 4.69$ \\
\hline Urine protein $(\mathrm{g} / 24 \mathrm{~h})^{*}$ & $3.36 \pm 2.53$ & $4.78 \pm 3.27$ \\
\hline Serum albumin $(\mathrm{g} / \mathrm{L})^{*}$ & $35.33 \pm 6.04$ & $31.17 \pm 8.74$ \\
\hline Nephrotic syndrome (\%) & $23(20.4)$ & $26(29.5)$ \\
\hline Uric acid $(\mu \mathrm{mol} / \mathrm{L})$ & $419.50 \pm 131.77$ & $392.53 \pm 133.41$ \\
\hline \multicolumn{3}{|l|}{ Pathologic } \\
\hline \multicolumn{3}{|l|}{ Oxford Classification } \\
\hline M1 (\%) & $105(92.9)$ & $83(94.3)$ \\
\hline E1 (\%) & $11(9.7)$ & $6(6.8)$ \\
\hline S1 (\%) & $75(66.4)$ & $61(69.3)$ \\
\hline $\mathrm{T} 1 / \mathrm{T} 2(\%)$ & $44(38.9)$ & $43(48.9)$ \\
\hline $\mathrm{C} 1 / \mathrm{C} 2(\%)$ & $41(36.3)$ & $28(31.8)$ \\
\hline
\end{tabular}
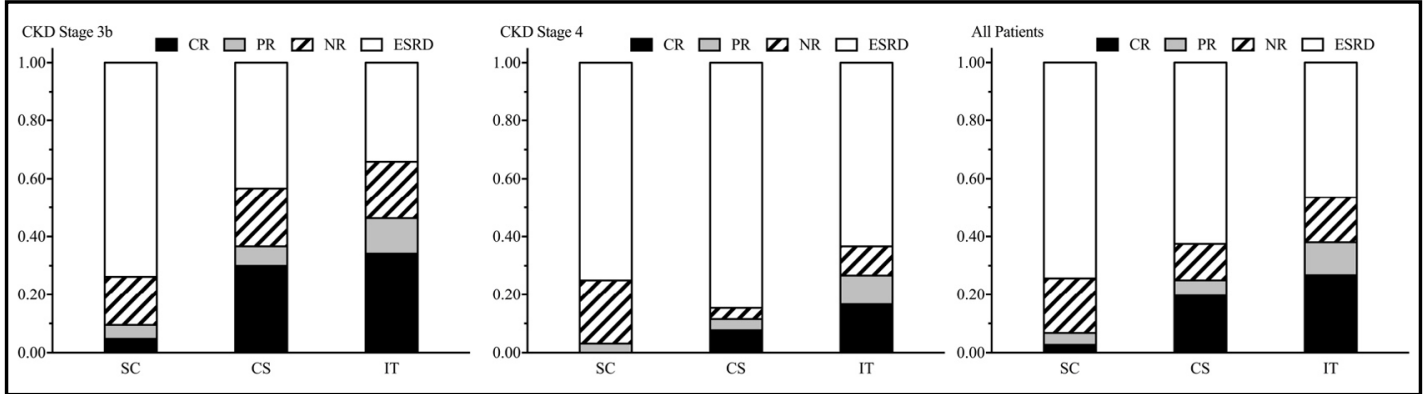

Fig. 2. Treatment response of IgA nephropathy patients. Abbreviations: CKD, chronic kidney disease; CR, complete remission; PR, partial remission; NR, no response; ESRD, end stage renal disease; SC, supportive care group; CS, corticosteroids; IT, immunosuppressive therapy.

Table 3. Therapy Responses according to Stages of CKD. Note: Values for categorical variables are given as number (percentage). Abbreviations: CKD, chronic kidney disease; CR, complete remission; PR, partial remission; NR, no response; ESRD, end stage renal disease; $\mathrm{SC}$, supportive care group; CS, corticosteroids; IT, immunosuppressive therapy

\begin{tabular}{lcccc}
\hline Parameter & CR & PR & NR & ESRD/ Death \\
\hline CKD stage 3b (n=113) & & & & \\
SC (n=42) & $2(4.8 \%)$ & $2(4.8 \%)$ & $7(16.7 \%)$ & $31(73.8 \%)$ \\
CS (n=30) & $9(30.0 \%)$ & $2(6.7 \%)$ & $6(20.0 \%)$ & $13(43.3 \%)$ \\
IT (n=41) & $14(34.1 \%)$ & $5(12.2 \%)$ & $8(19.5 \%)$ & $14(34.1 \%)$ \\
CKD stage 4 (n=88) & & & & \\
SC (n=32) & $0(0.0 \%)$ & $1(3.1 \%)$ & $4(12.5 \%)$ & $27(84.4 \%)$ \\
CS (n=26) & $2(7.7 \%)$ & $1(3.8 \%)$ & $1(3.8 \%)$ & $22(84.6 \%)$ \\
IT (n=30) & $5(16.7 \%)$ & $3(10.0 \%)$ & $3(10.0 \%)$ & $19(63.3 \%)$ \\
\hline
\end{tabular}




\section{Kidney Blood Pressure Research}

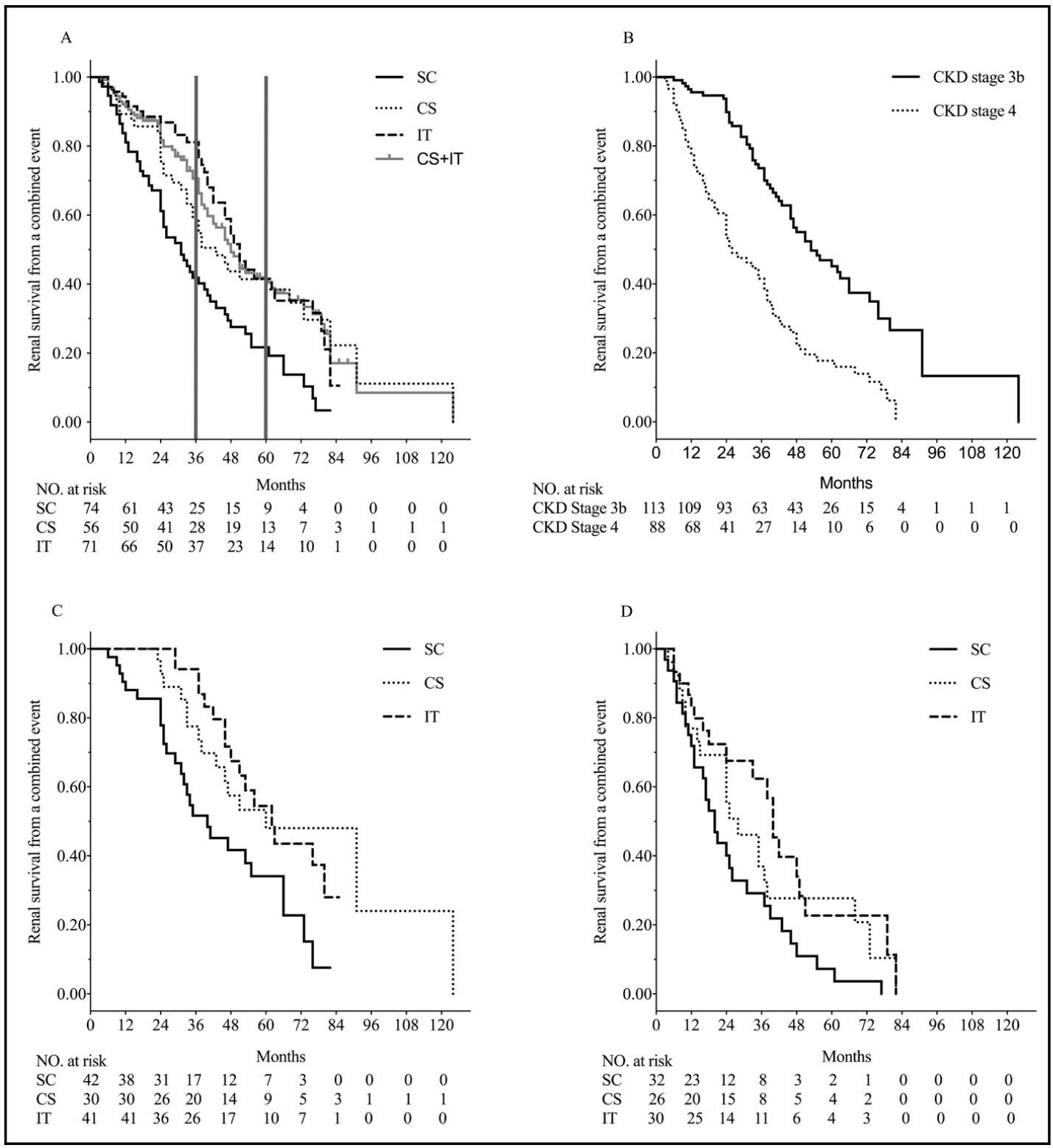

Fig. 3. Kaplan-Meier analysis for the probability of composite endpoint. Note: The primary endpoint was $50 \%$ decline in eGFR and/or ESRD. (A) Kidney survival rates in SC, CS and IT group; (B) Kidney survival rates in CKD stages $3 \mathrm{~b}$ and 4 groups. (C) Kidney survival rates in SC, CS and IT group in patients in stags $3 \mathrm{~b}$ CKD group. (D) Kidney survival rates in SC, CS and IT group in patients in stags 4 CKD group. Abbreviations: SC, supportive care group; CS, corticosteroids; IT, immunosuppressive therapy.

\section{Renal Survival}

As shown in Fig. 3A, K-M survival analysis showed 78.4\% (58 out of 74), 62.5\% (35 out of 56), and 49.3\% (35 out of 71) patients reached the combined endpoint in SC, CS, and IT groups respectively $(\mathrm{p}<0.001)$. However, there was no statistical significance between CS and IT groups ( $p=0.58)$, which suggested that, CS and IT could both improve the renal survival of IgAN patients, and the addition of immunosuppressants had no superiority to corticosteroids alone. It was found that 3-year renal survival rates in SC, CS, IT groups were $33.8 \%, 50.0 \%$ and $52.1 \%$, which showed a prominent statistical difference among groups $(\mathrm{p}<0.001)$. However, the 5-year renal survival rates were $12.2 \%, 23.2 \%$ and $19.7 \%$ 


\section{Kidney Blood Pressure Research}

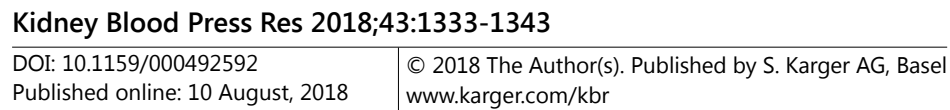
www.karger.com/kbr

Table 4. Cox Proportional Hazard Model for the Primary Endpoint in IgA Nephropathy Patients with CKD. Abbreviations: HR, hazard ratio; 95 \% CI, 95 \% confidence interval; M, mesangial proliferation; E, endocapillary proliferation; $\mathrm{S}$, segmental sclerosis; T, tubular atrophy/interstitial fibrosis; C, crescents. CKD, chronic kidney disease

\begin{tabular}{|c|c|c|c|c|}
\hline \multirow{2}{*}{ Parameter } & \multicolumn{2}{|c|}{ Unadjusted } & \multicolumn{2}{|c|}{ Adjusted } \\
\hline & HR $(95 \% \mathrm{CI})$ & $\mathrm{P}$ & HR $(95 \% \mathrm{CI})$ & $\mathrm{P}$ \\
\hline Hypertension & $2.92(1.82-4.68)$ & $<0.001$ & $2.44(1.51-3.95)$ & $<0.001$ \\
\hline Serum creatinine & $1.01(1.00-1.01)$ & $<0.001$ & $1.01(1.00-1.01)$ & $<0.001$ \\
\hline Urinary protein & $1.03(0.97-1.09)$ & 0.387 & $0.97(0.89-1.05)$ & 0.435 \\
\hline Serum albumin & $0.98(0.96-1.00)$ & 0.029 & $0.98(0.96-1.00)$ & 0.089 \\
\hline \multicolumn{5}{|c|}{ Oxford Classification } \\
\hline M1 & $1.26(0.46-3.43)$ & 0.650 & $1.10(0.40-3.05)$ & 0.849 \\
\hline E1 & $1.14(0.61-2.16)$ & 0.670 & $1.93(0.92-4.05)$ & 0.082 \\
\hline $\mathrm{S} 1$ & $0.90(0.62-1.33)$ & 0.605 & $0.76(0.50-1.13)$ & 0.176 \\
\hline $\mathrm{T} 1 / \mathrm{T} 2$ & $2.09(1.47-2.99)$ & $<0.001$ & $1.99(1.35-2.93)$ & 0.001 \\
\hline $\mathrm{C} 1 / \mathrm{C} 2$ & $1.63(1.09-2.46)$ & 0.019 & $0.65(0.41-1.04)$ & 0.070 \\
\hline
\end{tabular}

respectively, which is not statistically different $(\mathrm{p}=0.2)$. Furthermore, if supportive care (SC group) was compared with combined immunosuppressive treatment group (CS and IT groups), remarkable difference could be found in 3-year renal survival rates $(33.8 \%$ vs $51.1 \%, \mathrm{p}=0.02)$. However, no significant difference could be found in 5-year renal survival rates $(12.2 \%$ vs $21.3 \%, \mathrm{p}=0.1)$. These data indicated that immunosuppressive treatment (CS and IT) could improve 3-year renal survival of IgAN patients and avoid the early entrance into ESRD.

Analysis between groups indicated that kidney survival rates in stage $3 \mathrm{~b}$ group were remarkably higher than that in stage 4 CKD group (log-rank test: $p<0.001$; Fig. 3B). For patients in stage $3 \mathrm{~b}$ CKD group, we found that CS and IT could both improve the renal survival compared with SC group (log-rank test: $p=0.01$ and 0.003 ). While there was no significant difference between CS and IT groups (log-rank test: $p=0.9$; Fig. 3C). Further analysis found that for CKD stage 4 patients, steroids plus immunosuppressants could also improve renal survival (log-rank test: $p=0.008$; Fig. 3D).

\section{Renal failure predictors}

In Table 4, with 50\% decline in eGFR and/or ESRD as the combined endpoint, multivariate Cox regression analysis showed that independent risk factors influencing renal survival included hypertension (HR $=2.44,95 \%$ CI 1.51-3.95; $\mathrm{p}<0.001$ ), Scr (HR = 1.01, $95 \%$ CI 1.00-1.01; $\mathrm{p}<0.001)$, and T1-T2 lesion in pathological findings (HR $=1.99,95 \% \mathrm{CI}$ $1.35-2.93 ; \mathrm{p}=0.001)$.

\section{Discussion}

IgAN is one of the most common primary glomerulonephritis and a leading cause of ESRD. To date, the optimal treatment proposal for IgAN patients with impaired kidney function and remarkable proteinuria (proteinuria $>1 \mathrm{~g} / 24 \mathrm{~h}$ ) has being controversial. A large number of studies have shown conflicting conclusions $[4,12]$. Some studies revealed the use of corticosteroids and immunosuppressive therapy could lower the risk of progression to ESRD, improve remission of proteinuria, and reduce urinary protein excretion [3, 13-15]. However, STOP Trial and other studies indicated that corticosteroids and immunosuppressants might not provide substantial kidney related benefits [16-18]. Therefore, KDIGO guidelines only gave the recommendations that IgAN patients with an eGFR $>50 \mathrm{~mL} / \mathrm{min}$ per $1.73 \mathrm{~m}^{2}$ and a persistent proteinuria $\geq 1 \mathrm{~g} / \mathrm{d}$ should receive corticosteroid therapy. For IgAN patients with advanced kidney function and overt proteinuria, the utility of steroid or immunosuppressant is in dispute. Opinions supporting the use of steroid or immunosuppressant are based on the consensus that lowing proteinuria is an important protection for the progression 


\section{Kidney Blood Pressure Research}

Table 5. Demographic and Clinicopathologic Features of IgAN Patients after follow-up. Note: Values for continuous variables are given as mean \pm standard deviation or median (interquartile range). Abbreviations: SC, supportive care group; CS, corticosteroids; IT, immunosuppressive therapy

\begin{tabular}{lccc}
\hline Characteristics & \multicolumn{3}{c}{ Groups } \\
& $\mathrm{SC}(\mathrm{n}=74)$ & $\mathrm{CS}(\mathrm{n}=56)$ & $\mathrm{IT}(\mathrm{n}=71)$ \\
\hline Serum creatinine $(\mu \mathrm{mol} / \mathrm{L})^{*}$ & $712.0[370.0-871.0]$ & $376.0[151.0-892.0]$ & $193.0[127.0-533.0]$ \\
Urine protein $(\mathrm{g} / 24 \mathrm{~h})$ & $2.87 \pm 1.58$ & $2.12 \pm 1.52$ & $2.28 \pm 4.03$ \\
Serum albumin $(\mathrm{g} / \mathrm{L})$ & $35.0[32.0-41.0]$ & $38.0[33.0-42.0]$ & $40.0[33.0-4.02]$ \\
Uric acid $(\mu \mathrm{mol} / \mathrm{L})$ & $488.68 \pm 101.15$ & $467.02 \pm 90.56$ & $448.41 \pm 110.14$ \\
\hline
\end{tabular}

of kidney function, whereas opinions challenging this treatment argue that steroids or immunosuppressants might do more harm than good to these patients, such as causing hypertension, obesity, osteoporosis and infection. Clinically, nephrologists hold different ideas when dealing with these patients, especially when patients have heterogeneous disease activities, a reson why we can see various treatment strategies in this group of patients. In this article, we have reported the results of a cohort of IgAN subjects presenting with eGFR $<45 \mathrm{~mL} / \mathrm{min}$ per $1.73 \mathrm{~m}^{2}$ and overt proteinuria (proteinuria $>1 \mathrm{~g} / 24 \mathrm{~h}$ ) with the intention of providing new insights and offering new evidence for this constructive debate.

In this study, we found that steroids treatment with or without immunosuppressant was superior to SC alone in improving clinical manifestation in terms of reducing the increased level of Scr ( $p=0.02$, Table 5) and improving outcomes including response rate (CR $2.7 \%$ and PR 4.1\% in SC group, CR 19.6\% and PR 5.4\% in CS group, CR 26.8\% and PR $11.3 \%$ in IT group) and kidney survival $(78.4 \%, 62.5 \%$ and $49.3 \%$ reaching the combined endpoint in the SC, CS, and IT groups; $\mathrm{p}<0.001$ ). Moreover, 3-year renal survival rates in SC and CS/ IT groups were $33.8 \%$ vs $51.2 \%(p=0.02)$, and 5 -year renal survival rates were $12.2 \%$ vs $21.3 \%(p=0.1)$. However, there was no significant difference between CS group and IT group in terms of the overall prognosis (kidney survival, log-rank test: $p=0.6$ ).

Reviewing the literature, we could see physicians have been trying hard for years to find a desirable treatment strategy for IgAN patients. However, it's very difficult to standardize the regimen for patients with severity in different disease, pathological activity, and renal function. KDIGO guideline only recommended the use of steroids when patients have remarkable proteinuria and relatively normal renal function, because there were very little data on the use of corticosteroids in patients with eGFR $<50 \mathrm{ml} / \mathrm{min} / 1.73 \mathrm{~m}^{2}$. However, clinically we have numerous patients with significant proteinuria but not coming with an eGFR $>50 \mathrm{ml} / \mathrm{min} / 1.73 \mathrm{~m}^{2}$. Especially when histological findings indicate the disease might be aggressive and could benefit from steroids, different treatments for these patients make it even harder to summarize a preferable choice. Pozzi and colleagues reported a small group of IgAN patients with creatinine $>2 \mathrm{mg} / \mathrm{dL}$ treated with methylprednisolone plus azathioprine or steroid alone, concluding that six-year renal survival was similar but the addition of azathioprine may be slightly more effective than steroids alone in patients with chronic renal failure [19]. The recently published Testing study [18] trying to explore steroids treatment versus matching placebo for IgAN patients ended up in discontinuation because of significant adverse effect caused by steroids, even though the results were consistent with potential renal benefit. Testing study included 105 IgAN patients with eGFR $<50 \mathrm{~mL} / \mathrm{min} / 1.73 \mathrm{~m}^{2}$, although they did not analyse this group of patients separately, in their overall analysis the mean annual rate of eGFR decline in the steroids group was -1.79 $\mathrm{mL} / \mathrm{min} / 1.73 \mathrm{~m}^{2}$, compared with $-6.95 \mathrm{~mL} / \mathrm{min} / 1.73 \mathrm{~m}^{2}$ in the placebo group. Interestingly, in another clinical trial performed in China [20], MMF plus prednisone was found to be equal to full-dose prednisone in reducing proteinuria, but have fewer adverse events in patients with IgAN with proliferative lesions. However, this study recruited patients with relatively normal kidney function (mean eGFR $>90 \mathrm{~mL} / \mathrm{min} / 1.73 \mathrm{~m}^{2}$ in both groups). Just like other studies, immunosuppressant in our study was heterogeneous, since there has not been an outstanding choice yet. Although in our study the 5-year renal survival rates were almost equal among different groups, we did find a slightly better 3-year renal survival rate with 


\section{Kidney Blood Pressure Research}

immunosuppressive treatment (steroids alone or combined with immunosuppressant). Therefore, it's safe to say immunosuppressive treatment might have the advantage of postponing dialysis which has a high morbidity and is also a huge burden for both family and society.

More and more evidence suggested the association between pathological changes and clinical prognosis. It seems more reasonable to include pathological changes in the determination of clinical strategy since active proliferative lesions are predictors of poor clinical prognosis but fortunately reversible. In the clinical trial mentioned before [20], selecting patients with IgAN based on the presence of active proliferative lesions (cellular and fibrocellular crescents, endocapillary hypercellularity, or necrosis) led to a higher complete remission rate than previously reported trails based on eGFR and proteinuria only. This is also why physicians tend to choose steroids or immunosuppressant for advanced IgAN patients with relatively active pathological findings. In our study, by COX multivariate analysis, we found that hypertension, Scr, T1-T2 lesion were independent indicators of poor renal outcome. Our findings were consistent with many other studies showing that impaired kidney function, sustained hypertension predicted poor prognosis [4, 21]. Although several studies showed that crescents formation (C1/C2) was a risk factor of poor renal survival, multivariate analysis from our data only indicated a marginal relationship between $\mathrm{C}$ and primary endpoint $(\mathrm{p}=0.07$, Table 4$)$. Large sample clinical trials may give us more information about this point. However, to our best knowledge, there are no clinical trials including the MEST-C system into the study design yet.

Besides, the widely used CKD-EPI equation based on serum creatinine is controversial to estimate an accurate GFR, especially for Chinese population which has a large number of IgAN patients. Some studies are trying to find better equations for Chinese population but have not been recommended for clinical applications yet. Therefore, when considering the best treatment regimens for IgAN, which has a wide spectrum of clinical characteristics and histologic lesions, it seems arbitrary to refer only to eGFR and proteinuria level.

We have to say that this study has inevitable limitations. First, because of the retrospective nature of the data collection, we did not compare the different immunosuppressants used in all these patients. Second, the number of patients included in our study was not big enough. Moreover, all the patients included were from only a single ethnicity (Han Chinese). Considering that differences of genetic background may result in differentclinical and pathological features and even treatment effectiveness, studies in patients from other ethnicities may needed to verify our findings. Third, a mean follow-up period of only 37.2 months is relatively a short duration for such a slow progressing condition like IgAN, and it should be noted that, in Pozzi's trial, there was growing kidney survival advantage for as long as 10 years [4].

\section{Conclusion}

Compared with supportive care alone, corticosteroids with or without immunosuppressants might improve the renal outcome of patients with advanced IgAN. Discreetly designed prospective trails are needed to confirm this conclusion.

\section{Acknowledgements}

Funding: This study was partly supported by National Natural Science Foundation of China No. 81270793 and Sichuan University Science Foundation No. 2016SCU04B03.

Support: Sincere thanks should be given to Professor Ping Fu, Ye Tao, Zhangxue Hu, Baihai Su, Lichuan Yang and all the staff of Division of Nephrology, West China Hospital. 


\section{Kidney \\ Blood Pressure Research}

Contributions: Research idea and study design: WQ YT; data acquisition: WQ; data analysis/interpretation: LT, WP; statistical analysis: LT; supervision or mentorship: YT. Each author contributed important intellectual content during manuscript drafting or revision and accepts accountability for the overall work by ensuring that questions pertaining to the accuracy or integrity of any portion of the work are appropriately investigated and resolved. LT take responsibility that this study has been reported honestly, accurately, and transparently; that no important aspects of the study have been omitted; and that any discrepancies from the study as planned have been explained.

\section{Disclosure Statement}

The authors declare they have no conflicts of interest regarding this paper.

\section{References}

$>1$ Kim JK, Kim JH, Lee SC, Kang EW, Chang TI, Moon SJ, Yoon SY, Yoo TH, Kang SW, Choi KH, Han DS, Kie JH, Lim BJ, Jeong HJ,Han SH: Clinical features and outcomes of IgA nephropathy with nephrotic syndrome. Clin J Am Soc Nephrol 2012;7:427-436.

-2 Shu D, Xu F, Su Z, Zhang J, Chen C, Zhang J, Ding X, Lv Y, Lin H, Huang P: Risk factors of progressive IgA nephropathy which progress to end stage renal disease within ten years: a case-control study. BMC Nephrol 2017;18:11-17.

-3 Vecchio M, Bonerba B, Palmer SC, Craig JC, Ruospo M, Samuels JA, Molony DA, Schena FP, Strippoli GF: Immunosuppressive agents for treating IgA nephropathy. Cochrane Database Syst Rev 2015;8:CD003965.

$\rightarrow 4$ Coppo R: Corticosteroids in IgA Nephropathy: Lessons from Recent Studies. J Am Soc Nephrol 2017;28:2533.

5 KDIGO Work Group: KDIGO Clinical Practice Guideline for Glomerulonephritis. Kidney Int Suppl 2012:139274.

-6 Radhakrishnan J, Cattran DC: The KDIGO practice guideline on glomerulonephritis: reading between the (guide)lines-application to the individual patient. Kidney Int 2012;82:840-856.

7 Peng W, Tang Y, Jiang Z, Li Z, Mi X, Qin W: The effect of calcineurin inhibitors in the treatment of IgA nephropathy: A systematic review and meta-analysis (PRISMA). Medicine (Baltimore) 2016;95:e4731.

8 Al-Lawati AI, Reich HN: Is there a role for immunosuppression in immunoglobulin A nephropathy? Nephrol Dial Transplant 2017;32:i30-i36.

-9 Feehally J: Immunosuppression in IgA Nephropathy: Guideline Medicine Versus Personalized Medicine. Semin Nephrol 2017;37:464-477.

10 Cattran DC, Coppo R, Cook HT, Feehally J, Roberts IS, Troyanov S, Alpers CE, Amore A, Barratt J, Berthoux F, Bonsib S, Bruijn JA, D’Agati V, D’Amico G, Emancipator S, Emma F, Ferrario F, Fervenza FC, Florquin S, Fogo A, et al.: The Oxford classification of IgA nephropathy: rationale, clinicopathological correlations, and classification. Kidney Int 2009;76:534-545.

-11 Trimarchi, H, Barratt J, Cattran D C, Cook H T, Coppo R, Haas M, Liu Z H, Roberts I S, Yuzawa Y, Zhang H,Feehally J: Oxford Classification of IgA nephropathy 2016: an update from the IgA Nephropathy Classification Working Group. Kidney Int 2017;91:1014-1021.

$>12$ Rauen T, Fitzner C, Eitner F, Sommerer C, Zeier M, Otte B, Panzer U, Peters H, Benck U, Mertens PR, Kuhlmann U, Witzke O, Gross O, Vielhauer V, Mann JFE, Hilgers RD, Floege J: Effects of Two Immunosuppressive Treatment Protocols for IgA Nephropathy. J Am Soc Nephrol 2017;29:317-325.

13 Lv JC, Xu DM, Perkovic V, Ma XX, Johnson DW, Woodward M, Levin A, Zhang H, Wang HY, Grp TS: Corticosteroid Therapy in IgA Nephropathy. Journal of the American Society of Nephrology 2012;23:1108 1116.

14 Ballardie FW, Roberts IS: Controlled prospective trial of prednisolone and cytotoxics in progressive. J Am Soc Nephrol 2002;13:142-148. 


\section{Kidney \\ Blood Pressure Research}

15 Coppo R, Troyanov S, Bellur S, Cattran D, Cook HT, Feehally J, Roberts IS, Morando L, Camilla R, Tesar V, Lunberg S, Gesualdo L, Emma F, Rollino C, Amore A, Praga M, Feriozzi S, Segoloni G, Pani A, Cancarini G, et al.: Validation of the Oxford classification of IgA nephropathy in cohorts with different presentations and treatments. Kidney Int 2014;86:828-836.

-16 Rauen T, Eitner F, Fitzner C, Sommerer C, Zeier M, Otte B, Panzer U, Peters H, Benck U, Mertens PR, Kuhlmann U, Witzke O, Gross O, Vielhauer V, Mann JF, Hilgers RD, Floege J: Intensive Supportive Care plus Immunosuppression in IgA Nephropathy. N Engl J Med 2015;373:2225-2236.

17 Sarcina, C, Tinelli C, Ferrario F, Pani A, De Silvestri A, Scaini P, Del Vecchio L, Alberghini E, Buzzi L, Baragetti I,Pozzi C: Changes in Proteinuria and Side Effects of Corticosteroids Alone or in Combination with Azathioprine at Different Stages of IgA Nephropathy. Clinical Journal of the American Society of Nephrology 2016;11:973-981.

18 Lv J, Zhang H, Wong MG, Jardine MJ, Hladunewich M, Jha V, Monaghan H, Zhao M, Barbour S, Reich H, Cattran D, Glassock R, Levin A, Wheeler D, Woodward M, Billot L, Chan TM, Liu ZH, Johnson DW, Cass A, et al.: Effect of Oral Methylprednisolone on Clinical Outcomes in Patients With IgA Nephropathy: The TESTING Randomized Clinical Trial. JAMA 2017;318:432-442.

19 Claudio P, Andrulli S, Del Vecchio L, Melis P, Fogazzi GB, Altieri P, Ponticelli C, Locatelli F: Corticosteroid Effectiveness in IgA Nephropathy: Long-Term Results of a Randomized, Controlled Trial. J Am Soc Nephrol 2004;15:157-163.

20 Hou JH, Le WB, Chen N, Wang WM, Liu ZS, Liu D, Chen JH, Tian J, Fu P, Hu ZX, Zeng CH, Liang SS, Zhou ML, Zhang HT, Liu ZH: Mycophenolate Mofetil Combined With Prednisone Versus Full-Dose Prednisone in IgA Nephropathy With Active Proliferative Lesions: A Randomized Controlled Trial. Am J Kidney Dis 2017;69:788-795.

-21 Lv J, Xu D, Perkovic V, Ma X, Johnson DW, Woodward M, Levin A, Zhang H, Wang H, Group TS: Corticosteroid therapy in IgA nephropathy. J Am Soc Nephrol 2012;23:1108-1116. 